\title{
Crowdfunded Moon mission is serious about science
}

Celebrity-backed lander aims to drill the lunar south pole within a decade.

\section{Elizabeth Gibney}

19 November 2014 I Updated: 17 December 2014

\section{Lunar Mission One}

This conceptual animation shows how the lander would drill a hole in the Moon's surface and place a time capsule in it.

With government budgets for space exploration under strain, a UK consortium has embarked on a project to raise money for a robotic Moon mission by offering the public the chance to stash their memories and even a hair sample on the Moon.

The aim of Lunar Mission One is to put a lander on the Moon's south pole within the next decade. The robotic probe would to drill 20-100 metres into the surface, seeking insights about the origins of the Earth and the Moon, and paving the way for establishing a lunar base.

To fund the US\$1-billion enterprise, parent company Lunar Missions plans to turn the borehole into a time capsule and personal repository for paying customers. Its backers started soliciting contributions on 19 November, and had collected almost £90,000 (about $\$ 140,000)$ within the first 12 hours from its launch.

Sceptics doubt that there is enough interest to raise that much cash. But David Iron, who founded Lunar Missions and works on financing space projects at the consulting firm CGI, believes there is no harm in finding out. The consortium plans to raise an initial $£ 600,000$ on the crowdfunding platform Kickstarter by 17 December, to see there is enough interest to push ahead with the plans, he says. A second major fundraising push would go ahead in 2019, he says. "If the first phase fails, it implies there isn't the interest. There isn't really a plan B," he says.

[Update 17 December: With just 36 hours to go, Lunar Mission One has received pledges from more than 6,500 backers and has met its initial Kickstarter goal of $£ 600,000$. That money will go into financing the project's initial management and planning phase, the organisers say.] 
While NASA and the European Space Agency (ESA) have shelved lunar exploration plans in the past three years, Russia, China and Japan have planned lander missions to the Moon - and China successfully put its first rover there, called Chang'e 3 , at the end of 2013. Iron hopes that crowdsourcing will open a new vein of financing for space exploration. Everywhere except in China, "the 'boldly go' stuff is feeling the squeeze", says Iron.

Lunar Mission One has gathered support from a range of UK partners, including RAL Space, part of the UK Science and Technology Facilities Council, based near Oxford; University College London; and the Open University in Milton Keynes. The high-profile announcement also comes with the endorsement of dozens of UK scientists - including TV celebrity Brian Cox of the University of Manchester - and of two former UK science ministers, lan Taylor and David Willetts. Iron says that he hopes to involve international partners later.

"This looks like something real, if they can raise the money," says Jonathan McDowell, an astronomer at the Harvard-Smithsonian Center for Astrophysics in Cambridge, Massachusetts. He contrasts the clout of science expertise in the line-up, which includes lan Crawford, planetary scientist at Birkbeck University of London and the ESA Rosetta mission's Monica Grady, with most of the teams competing for the Google Lunar XPRIZE, whose aims are "light on the science side" and are working to a less realistic timetable of putting a lander on the Moon by the end of 2015 (see Moon shots stuck on Earth).

Other Kickstarter projects have raised more than $\$ 1$ million. The record stands at $\$ 13.3$ million, pledged to a company making multigadgeted cooling boxes. The pledges, made online, are collected only if a project reaches its target. For Lunar Mission One, \$1 million would allow the founders to establish management and legal arrangements and begin procurement. A detailed design would begin in 2017, and the main fundraising and sales drive would launch in 2019.

Sceptics doubt the shift from $\$ 1$ million to $\$ 1$ billion will be easy. "I know that this mission is only asking for a few hundred thousand [pounds], but just like many other crowd funded missions I see no realistic plan to actually raise enough to launch," says Chris Lintott, an astrophysicist at the University of Oxford.

"Market research tells us we can get the billion," says Iron. That is if, as the company's market research predicts, $1 \%$ of the people who can afford to invest - themselves a small fraction of the global population - each put in a few hundred dollars. If their predictions are correct, the drive would raise around $\$ 3$ billion, which would cover the creation of a non-profit trust to fund future space missions, including one to bring a lunar sample back to Earth, he adds.

Donors gain membership to the 'Lunar Missions Club', become part of an online community and are invited to events. Those who donate at least $£ 3,000(\$ 4,700)$ will have their name inscribed on the lunar landing module. The main product will be a 'digital memory box' that will go into the lunar borehole. Donors can record family trees or photographs in the box, and they may even be able to archive a strand of their hair, says Iron. The time capsule would also include a record of human history and a database of living species, developed with help from the public.

Adrian Sargeant, director of the Centre for Sustainable Philanthropy at Plymouth University, UK, says that crowdfunding is such a recent phenomenon that solid evidence about when it works and when it fails has yet to emerge. "Whether they succeed or not will depend on the extent to which they capture the public's imagination, he says.

This high $\$ 1$ billion target will be achievable only if the project manages to find and tap a fairly niche global community, says Elizabeth Ngonzi, a digital-engagement expert at the New York University Heyman Center for Fundraising and Philanthropy. "The types of people who would support this are not obvious to find," she says.

The mission appeals to lunar scientists. The Moon's south pole is thought to contain ice in its permanently shaded craters. Drilling in this little-explored region — and gaining access to pristine ancient rock — builds on ideas that the research community has proposed in the past, says Bernard Foing, a lunar scientist at ESA in Noordwijk, the Netherlands, who is not involved with the project. The technical challenge of drilling to such depths is high, he says. But the results could give insight into the impact history of the Moon and reveal organic molecules that could have been deposited by asteroids. "There is a strong science case," adds Foing. Because of its potential water reserves, the south pole is also where space-faring nations are most likely to establish a base in the coming century, says Iron.

No governments or space agencies are involved in the project at present, but Iron says that will probably change if the venture takes off. Although Lunar Mission One would use private contractors, the project will need to act under a government authority to avoid the 
legal complications that could come with a private venture drilling on the Moon, he adds.

[Update 17 December: In early December Crawford's team released a more detailed outline of the project's technical specifications and science objectives. The latter include studying the geochemistry of the lunar crust and assessing whether an astronomical observatory could be set up on the Moon.]

Nature | doi:10.1038/nature.2014.16378

\section{Updates}

Updated:The article has been modified with the addition of the news that the crowdfunding goal had been met and that the science team had published a more detailed plan. 